\title{
Internet Addiction and Its Associations with Clinical and Psychosocial Factors in Medical Students
}

\author{
Eun Hyun Seo', Seung-Gon Kim², Sang-Kyu Lee ${ }^{3}$, Seon-Cheol Park ${ }^{4}$, and Hyung-Jun Yoon ${ }^{2} \bowtie$ \\ ${ }^{1}$ Premedical Science, College of Medicine, Chosun University, Gwangju, Republic of Korea \\ ${ }^{2}$ Department of Psychiatry, College of Medicine, Chosun University, Gwangju, Republic of Korea \\ ${ }^{3}$ Department of Psychiatry, College of Medicine, Hallym University, Chuncheon, Republic of Korea \\ ${ }^{4}$ Department of Psychiatry, Hanyang University Guri Hospital, Guri, Republic of Korea
}

Objective Excessive internet use has been associated with various psychiatric symptoms and psychosocial factors. This study aimed to investigate the prevalence of internet addiction (IA) and its associations with clinical (depression/social anxiety) and psychosocial (selfesteem/perceived social support) factors in medical students.

Methods In total, 408 medical students at one university in Korea were included in this study. IA symptoms were assessed with Young's Internet Addiction Test, and scores of 50 or higher were considered to indicate IA. Participants were asked to complete the Beck Depression Inventory, Social Phobia Inventory, Rosenberg Self-Esteem Scale, and Duke-University of North Carolina Functional Social Support Questionnaire. A logistic regression model was constructed to examine the impact of clinical and psychosocial factors on IA.

Results Forty-seven participants (11.5\%) were identified as having IA. Self-esteem was associated with a lower risk of IA, whereas depression and social anxiety were associated with a higher risk of IA. Depression, social anxiety, low self-esteem, and low perceived social support were found to be significant correlates of IA. Young's Internet Addiction Test score positively correlated with Beck Depression Inventory and Social Phobia Inventory scores, but negatively correlated with Rosenberg Self-Esteem Scale and Duke-University of North Carolina Functional Social Support Questionnaire scores. Furthermore, the prevalence of IA was highest in first-year medical students.

Conclusion This study revealed the possible risk and protective factors of IA. Our findings indicate that strengthening self-esteem and reducing depression and social anxiety may contribute to the prevention and management of IA in medical students.

Psychiatry Investig 2021;18(5):408-416

Key Words Addiction, Depression, Internet, Self-esteem, Social anxiety, Social support.

\section{INTRODUCTION}

Internet technology has progressed rapidly over the past 20 years, and the internet has become an essential part of daily life. Proper use of the internet provides a novel communication medium that enables access to unlimited information resources across various topics and adds convenience to our daily lives. On the other hand, pathological or excessive use of the internet is associated with a variety of psychological and behavioral problems and may even lead to an addictive state, which

Received: November 10, 2020 Revised: January 8, 2021

Accepted: February 16, 2021

$\triangle$ Correspondence: Hyung-Jun Yoon, MD, MS

Department of Psychiatry, College of Medicine, Chosun University, 309 Pilmun-daero, Dong-gu, Gwangju 61452, Republic of Korea

Tel: +82-62-230-7365, Fax: +82-62-225-3659

E-mail: YoonHyungJun@chosun.ac.kr

(a) This is an Open Access article distributed under the terms of the Creative Commons Attribution Non-Commercial License (https://creativecommons.org/licenses/bync/4.0) which permits unrestricted non-commercial use, distribution, and reproduction in any medium, provided the original work is properly cited. is referred to as "internet addiction" (IA). ${ }^{1}$ Although not included as an official diagnosis in the fifth edition of the diagnostic and statistical manual of mental disorders, ${ }^{2}$ IA has attracted global attention due to its considerable prevalence and negative impacts on personal and public mental health, such as depression, social anxiety, distress, reduced happiness, social withdrawal, and suicide attempts. ${ }^{1,3}$ Young adults are considered to be especially susceptible to IA because of their growing up in an environment where smartphones or other internet-connected devices are available.

Undergraduate students belong to a particular population undergoing an important period of transition during which they are required to make major decisions and prepare for their future. In this critical phase of development, they may encounter diverse psychosocial stressors. As a response to this stress, some students become depressed or anxious. Depression and social anxiety in undergraduate students has been emphasized, since those symptoms have a negative effect on academic per- 
formance and quality of life. ${ }^{4,5}$ Medical students are a subgroup of students experiencing a significant level of psychological distress during the undergraduate period due to a variety of factors, including academic pressure, financial stress, sleep deprivation, and workload, and these issues can be emotionally challenging. ${ }^{6,7}$ Previous reviews have shown that psychological distress, including depression and anxiety, is more prevalent in medical students compared with the general population and age-matched peers. ${ }^{8}$ Internet can be used as a medium to cope with this psychological distress, since various online activities such as gaming, shopping, and social networking, provide pleasure. Moreover, in a 2-year prospective study of Taiwanese adolescents, the presence of underlying depression and social anxiety were found to predict the occurrence of IA. ${ }^{9}$

Self-esteem is a critical psychological variable closely related to psychopathology. According to Rosenberg, self-esteem is defined as the direction of self-attitude, a favorable or unfavorable opinion of oneself. An individual with high self-esteem respects himself or herself, and considers himself or herself worthy. ${ }^{10}$ Low self-esteem increases the risk of depression in adolescents, whereas high self-esteem has been shown to protect against depression. ${ }^{11}$ In addition, previous studies have demonstrated an association between self-esteem and addiction, suggesting that different levels of self-esteem may result in self-distrust, addictive personality, sense of loss of control, and a sense of failure. ${ }^{12}$ Therefore, level of self-esteem may be a significant predictor of IA. Social support refers to the various resources, materials, and emotions available to a person via interpersonal relationships. Perceived social support has been shown to have buffering effects and direct beneficial effects on well-being. ${ }^{13}$ In one epidemiological survey of a large sample, there was evidence for both beneficial and buffering effects of high perceived social support on mental health. ${ }^{14}$ Furthermore, a strong association was found between excellent self-perceived physical health and high perceived social support, suggesting the importance of perceived social support for mental and physical well-being. Meanwhile, low levels of perceived social support were found to be related to IA in adolescents. ${ }^{15,16}$

Medical students may be susceptible to IA because of their young age, the amount of time they spend using the internet for academic purposes, access to activities and resources, and medical training. Despite an increasing number of studies on the prevalence of IA and its correlates in medical students worldwide, there have been limited studies focusing on the association between IA and underlying clinical symptoms, self-esteem, and perceived social support. In addition, there have been few studies on the prevalence and related factors of IA in this population in Korea. Therefore, the present study aimed to investigate the prevalence of IA and its associations with clinical (depression/social anxiety) and psychosocial (self-esteem/perceived social support) factors in medical students.

\section{METHODS}

This cross-sectional study was conducted with 418 medical students at Chosun University in Gwangju Metropolitan City, Korea, from September 2019 to December 2019. Participants were selected using the convenience sampling method. Written informed consent was obtained after the purpose and procedures of the study had been explained by a researcher with no relationship to the medical students. Participants were made aware of the voluntary nature of the survey and that their information was completely anonymous and confidential. They then completed a self-report questionnaire on their sociodemographic characteristics (age, gender, year level, marital status, residence, religion, subjective body shape, subjective socioeconomic status, and subjective amount of pocket money), clinical symptoms (depression and social anxiety), and psychosocial factors (including self-esteem and perceived social support). The questionnaire was filled out in the presence of the researcher and returned to the researcher. To ensure confidentiality, participants were instructed to respond anonymously and to submit the questionnaire in a sealed envelope. A subset of participants were previously enrolled sample in the recently reported study. ${ }^{17}$ This study was conducted in accordance with the Declaration of Helsinki and was approved by the Institutional Review Board at Chosun University (IRB No. 2-1041055AB-N-01-2019-23).

\section{Measures}

\section{IA symptoms}

IA symptoms were assessed with Young's Internet Addiction Test (YIAT), which is a 20 -item scale that measures the presence and severity of IA. ${ }^{18}$ Each item of the YIAT is rated on a Likert scale of 0 (not applicable) to 5 (always), and the total score ranges from 0 to 100, with a higher score representing a higher level of severity of IA. Total scores between 0 and 30 indicate a normal level, 31 and 49 indicate a mild level, 50 and 79 indicate a moderate level, and 80 and 100 indicate a severe level. ${ }^{17}$ Based on previous research, ${ }^{19}$ participants scoring 50 or above were considered to have IA. The reliability and validity of the Korean version of the YIAT were confirmed. ${ }^{20}$ Cronbach's alpha for the YIAT was 0.94 in this sample.

\section{Depressive symptoms}

Depressive symptoms were assessed using the Beck Depression Inventory (BDI), which consists of 21 items. ${ }^{21}$ Each question enquires about the respondents' particular symptoms and changes in mood in the past week on a 4-point scale (from 0 
to 3), with a higher score representing more severe depressive symptoms. The validity and reliability of the scale in a Korean population have been previously confirmed and a cutoff score of 16 for depression has been suggested. ${ }^{22}$ Therefore, participants with a score of 16 or above were regarded as having depression. Cronbach's alpha for the BDI was 0.91 in this sample.

\section{Social anxiety symptoms}

Social anxiety symptoms were assessed with the Social Phobia Inventory (SPIN), which is a screening instrument to identify social anxiety. ${ }^{23}$ The scale consists of 17 items rated on a 5-point scale (from 0 to 4 ) and has three symptom domains: fear, avoidance, and physical symptoms. The total score ranges from 0 to 68 , with a higher score reflecting greater social anxiety. The reliability and validity of the SPIN have been previously confirmed in Korea. ${ }^{24}$ Based on previous studies, the cutoff score for social anxiety was 25 in this study. ${ }^{25,26}$ Cronbach's alpha of the SPIN was 0.93 in this sample.

\section{Self-esteem}

Self-esteem was measured using the Rosenberg Self-Esteem Scale (RSES). ${ }^{10}$ The RSES is a 10 -item self-administered questionnaire with 5 positive and 5 negative items reflecting high and low self-esteem, respectively. Each item is rated from 1 (strongly disagree) to 4 (strongly agree); however, negative items are reverse rated. The total score ranges from 10 to 40, with a higher score indicating higher self-esteem. The reliability and validity of the Korean version of the RSES were confirmed previously. ${ }^{27}$ Cronbach's alpha of the scale was 0.88 in this study.

\section{Perceived social support}

The Duke-University of North Carolina Functional Social Support Questionnaire (Duke-UNC FSSQ) was used to assess the degree of perceived social support. ${ }^{28}$ Eight items from the Duke-UNC FSSQ consisting of two subscales (confidant and affective support) were used to yield the mean score of social support. ${ }^{29}$ The confidant support subscale (5 items) measures the level of confidant support such as opportunities to discuss personal problems with someone else. The affective support subscale (3 items) measures the level of emotional support and care from family and friends. Each item is rated from 1 to 5 , with higher scores indicating a higher level of overall social support. The Korean version of the Duke-UNC FSSQ demonstrated high reliability and moderate validity in a previous study. ${ }^{30}$ Cronbach's alpha was found to be 0.93 in this study.

\section{Statistical analysis}

Participants were grouped into either an IA group or a nonIA group based on their YIAT score, with a cutoff of 50. Continuous variables were checked for normal distribution using the Kolmogorov-Smirnov test. Because all continuous data were non-normally distributed, nonparametric tests were used for the analysis. Group comparisons of sociodemographic characteristics; presence of depression and social anxiety; and mean BDI, SPIN, RSES, and Duke-UNC FSSQ scores were performed using the Mann-Whitney $\mathrm{U}$ test for continuous variables and the chi-square test or Fisher's exact test for categorical variables. A Spearman's rank correlation was performed to determine the correlation between IA severity and other variables of interest. Multivariate logistic regression analyses using the backwardconditional method were performed to identify the impacts of depression, social anxiety, self-esteem, and perceived social support on IA. The analysis was completed with depression, social anxiety, RSES, and Duke-UNC FSSQ scores as independent variables and the IA group and non-IA group as dependent variables. These analyses were performed using SPSS version 26.0 (IBM Corp., Armonk, NY, USA). All statistical analyses were two-tailed with a significance level set at $\mathrm{p}<0.05$.

\section{RESULTS}

\section{Prevalence of IA and associated sociodemographic characteristics}

A total of 418 medical students participated in this study. Ten invalid questionnaires (those with $>25 \%$ unanswered questions) were excluded, and 408 completed self-report questionnaires were analyzed. Of the 408 students included in the analysis, 255 (62.5\%) were men and 153 (37.5\%) were women. Ages ranged from 20 to 45 years, and the mean age was $26.3 \pm 4.4$ years. The overall prevalence of IA was $11.5 \%(n=47)$. The prevalence of IA was highest in first-year students $(n=21,17.5 \%)$, followed by fourth-year $(n=10,10.6 \%)$, second-year $(n=9,9.6 \%)$, and third-year $(n=7,7 \%)$ students, in that order. However, there were no significant differences with regard to sociodemographic factors between the IA and non-IA groups. The sociodemographic characteristics of the sample and comparisons by IA status are presented in Table 1.

\section{Clinical/psychosocial characteristics according to the presence of IA}

The prevalence rate of depression was significantly higher in the IA group compared with the non-IA group (IA group: $48.9 \%$, non-IA group: $8.9 \%$, $\mathrm{p}<0.001$ ). Moreover, the BDI scores were significantly higher in the IA group compared with the non-IA group $(\mathrm{p}<0.001)$. Similarly, the IA group showed a significantly higher rate of social anxiety (IA group: $51.1 \%$, non-IA group: $16.1 \%, \mathrm{p}<0.001)$ and higher scores in all three domains of the SPIN $(\mathrm{p}<0.001)$. However, the opposite was observed for the psychosocial factors. The RSES total scores, reflecting level of self-esteem, were significantly lower in the IA group 
Table 1. Group comparisons of sociodemographic characteristics according to the presence of internet addiction

\begin{tabular}{|c|c|c|c|c|c|}
\hline \multirow{2}{*}{$\begin{array}{c}\text { Sociodemographic } \\
\text { variables }\end{array}$} & \multicolumn{3}{|c|}{ Internet addiction } & \multirow[b]{2}{*}{$\chi^{2}$} & \multirow[b]{2}{*}{$\mathrm{p}$} \\
\hline & $\begin{array}{c}\text { No }(\text { YIAT< }<0) \\
361(88.5) \\
\end{array}$ & $\begin{array}{c}\text { Yes }(\mathrm{YIAT} \geq 50) \\
47(11.5)\end{array}$ & $\begin{array}{c}\text { Total } \\
408(100.0)\end{array}$ & & \\
\hline Age & $26.4 \pm 4.3$ & $26.0 \pm 4.7$ & $26.3 \pm 4.4$ & & $0.411^{*}$ \\
\hline Gender & & & & 0.01 & 0.904 \\
\hline Man & $226(62.6)$ & $29(61.7)$ & $255(62.5)$ & & \\
\hline Woman & $135(37.4)$ & $18(38.3)$ & $153(37.5)$ & & \\
\hline Year & & & & 6.64 & 0.084 \\
\hline First year & $99(27.4)$ & $21(44.7)$ & $120(29.4)$ & & \\
\hline Second year & $85(23.5)$ & $9(19.1)$ & $94(23.0)$ & & \\
\hline Third year & $93(25.8)$ & $7(14.9)$ & $100(24.5)$ & & \\
\hline Fourth year & $84(23.3)$ & $10(21.3)$ & $94(23.0)$ & & \\
\hline Marital status & & & & & $0.716^{\dagger}$ \\
\hline Never married & $342(94.7)$ & $46(97.9)$ & $388(95.1)$ & & \\
\hline Married & $19(5.3)$ & $1(2.1)$ & $20(4.9)$ & & \\
\hline Living place & & & & 3.13 & 0.210 \\
\hline With family & $116(32.2)$ & $10(21.3)$ & $126(31.0)$ & & \\
\hline In dormitory & $15(4.2)$ & $1(2.1)$ & $16(3.9)$ & & \\
\hline Alone & $229(63.6)$ & $36(76.6)$ & $265(65.1)$ & & \\
\hline Religion & & & & & $0.341^{\dagger}$ \\
\hline No & $188(52.1)$ & $29(61.7)$ & $217(53.2)$ & & \\
\hline Christianity & $107(29.6)$ & $10(21.3)$ & $117(28.7)$ & & \\
\hline Catholicism & $42(11.6)$ & $3(6.4)$ & $45(11.0)$ & & \\
\hline Buddhism & $21(5.8)$ & $5(10.6)$ & $26(6.4)$ & & \\
\hline Other religions & $3(0.8)$ & $0(0.0)$ & $3(0.7)$ & & \\
\hline Subjective body shape & & & & 3.22 & 0.200 \\
\hline Obese & $80(22.2)$ & $13(27.7)$ & $93(22.8)$ & & \\
\hline Average & $231(64.0)$ & $24(51.1)$ & $255(62.5)$ & & \\
\hline Slim & $50(13.9)$ & $10(21.3)$ & $60(14.7)$ & & \\
\hline Subjective SES & & & & 4.16 & 0.125 \\
\hline High & $67(18.6)$ & $13(27.7)$ & $80(19.6)$ & & \\
\hline Middle & $266(73.7)$ & $28(59.6)$ & $294(72.1)$ & & \\
\hline Low & $28(7.8)$ & $6(12.8)$ & $34(8.3)$ & & \\
\hline Subjective pocket money & & & & 0.22 & 0.896 \\
\hline Sufficient & $104(28.8)$ & $12(25.5)$ & $116(28.4)$ & & \\
\hline Moderate & $205(56.8)$ & $28(59.6)$ & $233(57.1)$ & & \\
\hline Insufficient & $52(14.4)$ & $7(14.9)$ & $59(14.5)$ & & \\
\hline
\end{tabular}

Data are presented as mean \pm standard deviation or $\mathrm{N}(\%) .{ }^{*}$ statistical significance test was done by Mann-Whitney U test, ${ }^{\dagger}$ statistical significance test was done by Fisher's exact test. YIAT: Young Internet Addiction Test, SES: socioeconomic status

compared with the non-IA group ( $\mathrm{p}<0.001)$. With regard to perceived social support, the Duke-UNC FSSQ total scores were significantly lower in the IA group compared with the non-IA group ( $\mathrm{p}=0.003)$. It was also found that both subscale scores of the Duke-UNC FSSQ were significantly lower in the IA group compared with the non-IA group (confidant support: $\mathrm{p}=0.005$, affective support: $\mathrm{p}=0.001$ ). The results of the group comparisons of the depression, social anxiety, and psychosocial factors are presented in Table 2.

\section{Correlations between IA symptoms and clinical/ psychosocial factors}

The YIAT total scores showed a significant positive correlation with the BDI $(\rho=0.335, p<0.01)$ and SPIN $(\rho=0.400$, $\mathrm{p}<$ $0.01)$ total scores. However, the RSES $(\rho=-0.336, p<0.01)$ and Duke-UNC FFSQ $(\rho=-0.215, p<0.01)$ total scores showed a significant negative association with the YIAT total scores. Spearman's $\rho$ for IA symptoms with depression, social anxiety, self-esteem, and perceived social support are shown in Table 3. 


\section{Impact of clinical/psychosocial factors on IA}

To identify the variables associated with IA, multivariate logistic regression analyses were performed. All variables showing statistically significant differences between the IA group and the non-IA group were entered and analyzed using the backward method. In addition, gender and age were included as potential confounders in the regression model. In the good- ness-of-fit test of the regression model, the $-2 \log$ likelihood was 234.464, indicating statistical significance $(\mathrm{p}<0.001)$. Gender [odds ratio $(\mathrm{OR})=0.633,95 \%$ confidence interval $(\mathrm{CI}) 0.298^{-}$ $1.347, \mathrm{p}=0.235$ ], age $(\mathrm{OR}=1.009,95 \% \mathrm{CI} 0.932-1.091, \mathrm{p}=0.833)$, and perceived social support $(\mathrm{OR}=1.025,95 \% \mathrm{CI} 0.970-1.084$, $\mathrm{p}=0.379$ ) had no statistically significant effect on IA in the first model tested, and were thus removed from the final model.

Table 2. Group comparisons of clinical symptoms and psychosocial factors according to the presence of internet addiction

\begin{tabular}{|c|c|c|c|c|c|}
\hline \multirow{2}{*}{ Variables } & \multicolumn{3}{|c|}{ Internet addiction } & \multirow{2}{*}{$\chi^{2}$} & \multirow{2}{*}{$\mathrm{p}$} \\
\hline & No $($ YIAT< <50) & Yes $($ YIAT $\geq 50)$ & Total & & \\
\hline \multicolumn{6}{|l|}{ Clinical symptoms } \\
\hline Depression & & & & 57.25 & $<0.001$ \\
\hline Yes $(\mathrm{BDI} \geq 16)$ & $32(8.9)$ & $23(48.9)$ & $55(13.5)$ & & \\
\hline No $(\mathrm{BDI}<16)$ & $329(91.1)$ & $24(51.1)$ & $353(86.5)$ & & \\
\hline BDI total & $6.6 \pm 6.2$ & $14.5 \pm 10.3$ & $7.5 \pm 7.3$ & & $<0.001^{*}$ \\
\hline Social anxiety & & & & 31.72 & $<0.001$ \\
\hline Yes (SPIN $\geq 25)$ & $58(16.1)$ & $24(51.1)$ & $82(20.1)$ & & \\
\hline No $(\mathrm{SPIN}<25)$ & $303(83.9)$ & $23(48.9)$ & $326(79.9)$ & & \\
\hline SPIN total & $14.9 \pm 10.1$ & $26.3 \pm 15.2$ & $16.2 \pm 11.4$ & & $<0.001^{*}$ \\
\hline \multicolumn{6}{|l|}{ SPIN component } \\
\hline Fear & $6.2 \pm 4.0$ & $10.6 \pm 5.9$ & $6.7 \pm 4.5$ & & $<0.001^{*}$ \\
\hline Avoidance & $7.0 \pm 4.8$ & $11.6 \pm 6.7$ & $7.5 \pm 5.3$ & & $<0.001^{*}$ \\
\hline Physical symptoms & $1.8 \pm 2.3$ & $4.0 \pm 3.6$ & $2.0 \pm 2.6$ & & $<0.001^{*}$ \\
\hline \multicolumn{6}{|l|}{ Psychosocial factors } \\
\hline \multicolumn{6}{|l|}{ Self-esteem } \\
\hline RSES total & $31.9 \pm 5.0$ & $25.8 \pm 7.0$ & $31.2 \pm 5.6$ & & $<0.001^{*}$ \\
\hline \multicolumn{6}{|l|}{ Perceived social support } \\
\hline Duke-UNC FSSQ total & $33.6 \pm 6.3$ & $29.5 \pm 8.9$ & $33.1 \pm 6.7$ & & $0.003^{*}$ \\
\hline \multicolumn{6}{|c|}{ Duke-UNC FSSQ component } \\
\hline Confidant support & $20.4 \pm 4.3$ & $18.0 \pm 5.6$ & $20.1 \pm 4.6$ & & $0.005^{*}$ \\
\hline Affective support & $13.2 \pm 2.4$ & $11.5 \pm 3.4$ & $13.0 \pm 2.6$ & & $0.001^{*}$ \\
\hline
\end{tabular}

Data are presented as mean \pm standard deviation or $\mathrm{N}(\%) .{ }^{*}$ statistical significance test was done by Mann-Whitney U test. YIAT: Young Internet Addiction Test, BDI: Beck Depression Inventory, SPIN: Social Phobia Inventory, RSES: Rosenberg Self-Esteem Scale, Duke-UNC FSSQ: Duke-University of North Carolina Functional Social Support Questionnaire

Table 3. Spearman's rank correlation of internet addiction symptoms, depressive symptoms, social anxiety symptoms, selfesteem, and perceived social support

\begin{tabular}{llllll}
\hline & \multicolumn{1}{c}{1} & \multicolumn{1}{c}{2} & \multicolumn{1}{c}{3} & \multicolumn{1}{c}{4} & 5 \\
\hline 1. YIAT & 1 & & & & \\
2. BDI & $0.335^{*}$ & 1 & & & \\
3. SPIN & $0.400^{*}$ & $0.476^{*}$ & 1 & & \\
4. RSES & $-0.336^{*}$ & $-0.592^{*}$ & $-0.493^{*}$ & 1 & \\
5. Duke-UNC FSSQ & $-0.215^{*}$ & $-0.480^{*}$ & $-0.435^{*}$ & $0.430^{*}$ & 1 \\
\hline
\end{tabular}

${ }^{*} \mathrm{p}<0.01$. YIAT: Young Internet Addiction Test, BDI: Beck Depression Inventory, SPIN: Social Phobia Inventory, RSES: Rosenberg Self-Esteem Scale, Duke-UNC FSSQ: Duke-University of North Carolina Functional Social Support Questionnaire
Table 4. Logistic regression analysis for factors associated with internet addiction

\begin{tabular}{lccccc}
\hline Variable & $\mathrm{B}$ & $\mathrm{SE}$ & Wald & $\mathrm{p}$ & OR $(95 \% \mathrm{CI})$ \\
\hline $\begin{array}{l}\text { Depression } \\
\text { Yes (BDI } \geq 16)\end{array}$ & 1.229 & 0.447 & 7.550 & 0.006 & $\begin{array}{c}3.418 \\
(1.422-8.213)\end{array}$ \\
$\begin{array}{c}\text { Social anxiety } \\
\text { Yes (SPIN } \geq 25)\end{array}$ & 0.904 & 0.374 & 5.846 & 0.016 & $\begin{array}{c}2.468 \\
(1.187-5.134)\end{array}$ \\
$\begin{array}{l}\text { Self-esteem } \\
\text { RSES total }\end{array}$ & -0.086 & 0.033 & 6.713 & 0.010 & $\begin{array}{c}0.918 \\
(0.860-0.979)\end{array}$ \\
\hline
\end{tabular}

$\chi^{2}$ of model $=56.801, \mathrm{df}=3$, Nagelkerke $\mathrm{R}^{2}=0.255$. BDI: Beck Depression Inventory, SPIN: Social Phobia Inventory, RSES: Rosenberg Self-Esteem Scale, OR: odds ratio, CI: confidence interval 
Table 4 shows the final model of the analysis. RSES total scores ( $\mathrm{OR}=0.918,95 \%$ CI $0.860-0.979, \mathrm{p}=0.010)$, presence of depression $(\mathrm{OR}=3.418,95 \% \mathrm{CI} 1.422-8.213, \mathrm{p}=0.006)$, and social anxiety $(\mathrm{OR}=2.468,95 \% \mathrm{CI} 1.187-5.134, \mathrm{p}=0.016)$ were all significantly associated with IA. The Nagelkerke R-squared statistic for the final model was 0.255 .

\section{DISCUSSION}

Identifying the risk and protective factors for IA is important for both research and clinical practice. In this study, we analyzed the association between both clinical and psychosocial factors and IA in a sample of Korean medical students. The presence of underlying depression and social anxiety was found to be a significant risk factor for the occurrence of IA, whereas self-esteem was associated with a lower risk of IA. IA symptom severity was positively correlated with the severity of depressive and social anxiety symptoms. However, self-esteem and perceived social support were negatively correlated with IA symptom severity. Depression, social anxiety, low self-esteem, and low perceived social support were significantly correlated with IA.

The prevalence rate of IA in the sample was $11.5 \%$. This rate was higher than those of previous studies in Greek and Thai medical students, ${ }^{31,32}$ and was comparable to those of previous studies on Chinese medical students. ${ }^{33}$ However, this rate was lower compared with what has been reported in some other samples of medical students from India and Nepal reporting prevalence rates ranging from $18.5 \%$ to $44.6 \%{ }^{34,35}$ and $30.1 \%$ in a recent meta-analysis. ${ }^{36}$ The differences in prevalence rates across studies may be due to different instruments, different cutoff points, and cultural differences with regard to internet use. In one meta-analysis, the global prevalence of IA was found to be $6 \%$ in 31 countries across 7 world regions. ${ }^{37}$ Similarly, the prevalence of IA evaluated by the YIAT was reported to be $5 \%$ in samples of adolescents from 6 different Asian countries. ${ }^{38}$ The prevalence of IA in the present study was about two times higher than that of the general population and university students in general, ${ }^{39}$ suggesting that medical students may be especially vulnerable to IA. IA is associated with cognitive impairment, which can affect academic performance and quality of life. ${ }^{37}$ Furthermore, a significant correlation between IA and academic procrastination in medical students has previously been shown. ${ }^{40}$ Considering the high prevalence of IA and its negative effect on academic performance and quality of life, active efforts to perform screenings and conduct interventions for IA should be undertaken at medical schools. From the perspective of medical education, educators need to be familiar with distinct signs of IA, such as difficulty reducing internet use and withdrawal, and to refer medical students with potential
IA to mental health professionals. Additionally, adding IA to the curriculum may increase awareness of the condition and therapeutic modalities, such as cognitive behavioral therapy and psychotropic medications, among medical students.

Researchers are interested in studying depression in medical students because depressive symptoms are common in this group and are associated with suicide ideation and suicide attempts. ${ }^{8,41}$ Individuals with depression often experience loneliness, loss of pleasure, and lack of motivation, which could drive them to use the internet to overcome these emotions. ${ }^{42}$ Conversely, individuals who spend an excessive amount of time using the internet may be isolated from social interaction and predisposed to depression. Hence, both depression and IA can interact with each other and aggravate both conditions. ${ }^{43,44} \mathrm{Al}-$ though the number of studies on the association between depression and IA is limited, the results of our study provide evidence of this reciprocal relationship. Specifically, the presence of depression showed the strongest association with IA, suggesting that underlying depressive symptoms may be an important risk factor for IA in medical students. With regard to social anxiety, we found that individuals with social anxiety had an increased probability of having IA. Previous research found that social anxiety was positively associated with internet use in adolescents, ${ }^{45}$ and the avoidance domain of social anxiety was the strongest predictor of IA severity in a sample of medical students, ${ }^{46}$ implying that social anxiety plays an important role in IA. Furthermore, our results revealed that all three domains of the SPIN and overall social anxiety, were associated with IA symptoms. This suggests that fear, physical symptoms, and avoidance (three main aspects of social anxiety) may impact IA in medical students. Socially anxious individuals are motivated to seek low-risk communicative encounters. ${ }^{47}$ Medical students may view online communication as a safe method of avoiding fearful face-to-face interactions. In line with this notion, social anxiety was found to be a significant predictor of a preference for online social interaction. ${ }^{48}$ Internet use as a low-risk social approach may provide an opportunity to rehearse social skills, which may help socially anxious individuals to overcome their social anxiety. ${ }^{49}$ Pathological use of the internet can exacerbate social anxiety and isolation. Given the meaningful associations of depression and social anxiety with IA, medical students who have both may be at an especially high risk for IA. In sum, our findings suggest that underlying depression and social anxiety should be considered in the prevention and management of IA in medical students.

Medical students with IA showed a lower level of self-esteem compared to those without IA, and an inverse correlation of self-esteem with IA was found. In addition, logistic regression analysis indicated that individuals with higher levels of selfesteem had a reduced probability of having IA. There is increas- 
ing evidence that high self-esteem is a strong protective factor against IA in adolescents. ${ }^{50}$ On the other hand, in a previous report from a large national survey, low self-esteem was found to be associated with IA severity. ${ }^{51}$ Our findings suggest that self-esteem can play an important role in the prevention of IA in medical students. In line with the results of this study, it was found that self-esteem had a protective effect on IA severity and negatively correlated with IA symptoms in a sample of Turkish medical students. ${ }^{46}$ For individuals with low self-esteem, online activities can compensate for their perceived deficiency, and increasing use of the internet may reach the level of addiction. ${ }^{50}$ In the present study, the level of perceived social support was significantly lower in individuals with IA compared to those without IA and negatively correlated with IA severity. These results support previous evidence of an inverse correlation between IA and social support. ${ }^{15,16}$ In addition, low levels of both confidant and affective support were found to be significant correlates of IA, suggesting that confidant relationships and affective aspect of social support may be closely associated with IA. Supportive relationships can be a useful resource for medical students to effectively manage their psychological distress and stressors. Given the previous association between stressors from interpersonal problems and IA, good social support can reduce the prevalence of IA in medical students. Nevertheless, perceived social support was unable to predict IA significantly in logistic regression analysis, suggesting that lower perceived social support may be a result of IA rather than a risk factor for IA. This is consistent with the findings of Karaer and Akdemir, ${ }^{16}$ who found that social support was not a significant predictor of IA. In contrast, Wu et al. ${ }^{15}$ reported that social support had a negative predictive effect on IA. With regard to these mixed findings, there is a possibility that other clinical/psychosocial factors may have mediated the relationship. In addition, the different scales may partly account for this difference because a variety of scales were used to evaluate perceived social support across studies. Despite the potential protective effect of social support on excessive internet use, studies focusing on the association between perceived social support and IA are limited. Thus, additional longitudinal studies are needed to examine the role of perceived social support on IA in medical students.

Interestingly, the present study did not find any significant differences in any of the sociodemographic variables between the IA and non-IA groups. The prevalence rate of IA did not differ according to gender in our study, implying that medical students of both genders are equally susceptible to IA. This is in line with findings of previous studies ${ }^{31,33,46}$ and a meta-anal$y{ }^{36}{ }^{36}$ reporting that gender proportions did not account for the heterogeneity in the pooled prevalence of IA in medical students. This result could be due to the fact that, among medical students, men and women have equal opportunities to use the internet. Another study reported that IA behaviors were significantly higher in medical students who were men. ${ }^{52}$ Being a man has also been reported to be a risk factor for IA in adolescents. ${ }^{53}$ Further studies are required to elucidate the gender differences in medical students with IA. Although a significant difference was not found between the two groups in terms of age and year level, the prevalence of IA was highest in first-year students. This finding is consistent with those of a study of Malaysian medical students. ${ }^{54}$ The first year of medical school may be an important transitional period in which students develop self-control to manage academic pressure and environmental demands. First-year medical students who lack self-control due to low parental monitoring may be at risk for IA. This issue should be considered by health professionals. In our study, there were no significant differences between the two groups in the levels of subjective socioeconomic status and subjective pocket money. However, lower family income was found to be a significant correlate of IA in a sample of Turkish medical students. ${ }^{46}$ Students in families with higher income are able to afford more leisure activities, whereas those with low income may use the internet more frequently because it is cheap and easy to access. Thus, the relationship between objective socioeconomic status and IA should be further investigated.

This study had several limitations. First because this was a cross-sectional study, causality could not be established between IA and depression, social anxiety, and self-esteem. Prospective studies are needed to confirm the causal relationships between IA and these clinical/psychosocial variables. Second, as the study population was limited to those attending one medical college in a specific city, the sample may not represent all Korean medical students. Third, we did not conduct interviews to confirm the diagnosis of IA and psychiatric comorbidities. Additional clinical interviews with those scoring a cutoff score of the YIAT would be helpful to shed more light on the correlates of IA. Fourth, there is the possibility of sampling bias since the selection of participants was based on the convenience method, limiting the generalizability of our findings. Fifth, this study did not assess specific and major issues related to IA in medical students such as school life, academic performance, and purpose of using the internet. Hence, future studies on these issues are required to develop specialized programs for medical students with IA. Sixth, considering the relatively lower explained variance of clinical and psychosocial factors, other factors such as academic burden and the hierarchical culture of medical school warrant further investigation. Finally, owing to the nature of self-rating measures, the results of this study should be interpreted carefully. However, participants were guaranteed confidentiality by anonymity, which can reduce the possibility of deception. 
In conclusion, our study demonstrated significant associations between IA and depression, social anxiety, and self-esteem in a sample of medical students. Although the relationship between various clinical/psychosocial factors and IA is not yet fully understood, our findings suggest that enhancing self-esteem and decreasing depression and social anxiety could play an important role in the prevention and management of IA in this group. The level of perceived social support was found to be a significant correlate rather than a predictor of IA, which needs to be confirmed in future research. Furthermore, the prevalence of IA was found to be highest in first-year medical students, which should be considered when dealing with the mental health issues of medical students. These findings can potentially aid in the development of prevention and intervention programs for IA in medical students.

\section{Acknowledgments}

This study was supported by research fund from Chosun University (2020).

\section{Conflicts of Interest}

The authors have no potential conflicts of interest to disclose.

\section{Author Contributions}

Conceptualization: Eun Hyun Seo, Hyung-Jun Yoon. Data curation: Eun Hyun Seo, Hyung-Jun Yoon. Formal analysis: Eun Hyun Seo, Hyung-Jun Yoon. Investigation: Hyung-Jun Yoon. Methodology: all authors. Writing_original draft: Eun Hyun Seo, Hyung-Jun Yoon. Writing_-review \& editing: all authors. Approval of final manuscript: all authors.

\section{ORCID iDs}

$\begin{array}{ll}\text { Eun Hyun Seo } & \text { http://orcid.org/0000-0002-4764-7464 } \\ \text { Seung-Gon Kim } & \text { http://orcid.org/0000-0002-5000-7222 } \\ \text { Sang-Kyu Lee } & \text { http://orcid.org/0000-0001-6714-850X } \\ \text { Seon-Cheol Park } & \text { http://orcid.org/0000-0003-3691-4624 } \\ \text { Hyung-Jun Yoon } & \text { http://orcid.org/0000-0003-3087-8853 }\end{array}$

\section{REFERENCES}

1. Cerniglia L, Zoratto F, Cimino S, Laviola G, Ammaniti M, Adriani W. Internet Addiction in adolescence: neurobiological, psychosocial and clinical issues. Neurosci Biobehav Rev 2017;76:174-184.

2. American Psychiatric Association. DSM-5 Task Force. Diagnostic and Statistical Manual of Mental Disorders: DSM-5. Washington, D.C.: American Psychiatric Association; 2013.

3. Akın A. The relationships between Internet addiction, subjective vitality, and subjective happiness. Cyberpsychol Behav Soc Netw 2012;15: 404-410.

4. Hysenbegasi A, Hass SL, Rowland CR. The impact of depression on the academic productivity of university students. J Ment Health Policy Econ 2005;8:145-151.

5. Baptista CA, Loureiro SR, de Lima Osório F, Zuardi AW, Magalhães PV, Kapczinski F, et al. Social phobia in Brazilian university students: prevalence, under-recognition and academic impairment in women. J Affect Disord 2012;136:857-861.

6. Wolf TM, Faucett JM, Randall HM, Balson PM. Graduating medical students' ratings of stresses, pleasures, and coping strategies. J Med Educ 1988;63:636-642.

7. Stewart SM, Lam TH, Betson CL, Wong CM, Wong AM. A prospective analysis of stress and academic performance in the first two years of medical school. Med Educ 1999;33:243-250.

8. Dyrbye LN, Thomas MR, Shanafelt TD. Systematic review of depression, anxiety, and other indicators of psychological distress among U.S. and Canadian medical students. Acad Med 2006;81:354-373.

9. Ko CH, Yen JY, Chen CS, Yeh YC, Yen CF. Predictive values of psychiatric symptoms for internet addiction in adolescents: a 2-year prospective study. Arch Pediatr Adolesc Med 2009;163:937-943.

10. Rosenberg M. Society and the Adolescent Self-Image. Princeton, NJ: Princeton University Press; 1965.

11. Costello DM, Swendsen J, Rose JS, Dierker LC. Risk and protective factors associated with trajectories of depressed mood from adolescence to early adulthood. J Consult Clin Psychol 2008;76:173-183.

12. Greenberg JL, Lewis SE, Dodd DK. Overlapping addictions and selfesteem among college men and women. Addict Behav 1999;24:565-571.

13. Cohen S, Wills TA. Stress, social support, and the buffering hypothesis. Psychol Bull 1985;98:310-357.

14. Moak ZB, Agrawal A. The association between perceived interpersonal social support and physical and mental health: results from the $\mathrm{Na}$ tional Epidemiological Survey on Alcohol and Related Conditions. J Public Health 2010;32:191-201.

15. Wu XS, Zhang ZH, Zhao F, Wang WJ, Li YF, Bi L, et al. Prevalence of Internet addiction and its association with social support and other related factors among adolescents in China. J Adolesc 2016;52:103-111.

16. Karaer Y, Akdemir D. Parenting styles, perceived social support and emotion regulation in adolescents with internet addiction. Compr Psychiatry 2019;92:22-27.

17. Lee SE, Kim SG, Kim SH, Park SH, Seo EH, Yoon HJ. Association of social anxiety disorder symptoms with self-esteem, ego-resiliency and social support in medical students. Anxiety Mood 2020;16:98-105.

18. Internet Addiction Test (IAT) Manual. Available at: http://cyberpsy.ru/ wp-content/uploads/2018/02/iat-manual.pdf. Accessed September 7, 2020.

19. Tateno M, Teo AR, Shiraishi M, Tayama M, Kawanishi C, Kato TA. Prevalence rate of Internet addiction among Japanese college students: Two cross-sectional studies and reconsideration of cut-off points of Young's Internet Addiction Test in Japan. Psychiatry Clin Neurosci 2018; 72:723-730

20. Lee K, Lee HK, Gyeong H, Yu B, Song YM, Kim D. Reliability and validity of the Korean version of the internet addiction test among college students. J Korean Med Sci 2013;28:763-768.

21. Beck AT, Ward CH, Mendelson M, Mock J, Erbaugh J. An inventory for measuring depression. Arch Gen Psychiatry 1961;4:561-571.

22. Shin MS, Kim ZS, Park KB. The cut-off score for the Korean version of Beck Depression Inventory. Korean J Clin Psychol 1993;12:71-81.

23. Connor KM, Davidson JR, Churchill LE, Sherwood A, Foa E, Weisler RH. Psychometric properties of the Social Phobia Inventory (SPIN). New self-rating scale. Br J Psychiatry 2000;176:379-386.

24. Cho Y, Choi Y, Kim S, Hong S. Factor structure and other psychometric properties of the social phobia inventory in Korean samples. Meas Eval Couns Dev 2018;51:263-280.

25. Sosic Z, Gieler U, Stangier U. Screening for social phobia in medical in-and outpatients with the German version of the Social Phobia Inventory (SPIN). J Anxiety Disord 2008;22:849-859.

26. Tsai CF, Wang SJ, Juang KD, Fuh JL. Use of the Chinese (Taiwan) version of the Social Phobia Inventory (SPIN) among early adolescents in rural areas: reliability and validity study. J Chin Med Assoc 2009;72: 422-429.

27. Bae HN, Choi SW, Yu JC, Lee JS, Choi KS. Reliability and validity of the Korean version of the Rosenberg Self-Esteem Scale (K-RSES) in adult. Mood Emot 2014;12:43-49.

28. Broadhead WE, Gehlbach SH, de Gruy FV, Kaplan BH. The DukeUNC Functional Social Support Questionnaire. Measurement of social support in family medicine patients. Med Care 1988;26:709-723.

29. Broadhead WE, Kaplan BH. Social support and the cancer patient. Implications for future research and clinical care. Cancer 1991;67:794- 
799.

30. Suh SY, Im YS, Lee SH, Park MS, Yoo T. A study for the development of Korean version of the Duke-UNC functional social support questionnaire. J Korean Acad Fam Med 1997;18:250-260.

31. Tsimtsiou Z, Haidich AB, Spachos D, Kokkali S, Bamidis P, Dardavesis $\mathrm{T}$, et al. Internet addiction in Greek medical students: an online survey. Acad Psychiatry 2015;39:300-304.

32. Simcharoen S, Pinyopornpanish M, Haoprom P, Kuntawong P, Wongpakaran N, Wongpakaran T. Prevalence, associated factors and impact of loneliness and interpersonal problems on internet addiction: a study in Chiang Mai medical students. Asian J Psychiatr 2018;31:2-7.

33. Shi M, Du TJ. Associations of personality traits with internet addiction in Chinese medical students: the mediating role of attention-deficit/hyperactivity disorder symptoms. BMC Psychiatry 2019;19:183.

34. Gedam SR, Shivji IA, Goyal A, Modi L, Ghosh S. Comparison of internet addiction, pattern and psychopathology between medical and dental students. Asian J Psychiatr 2016;22:105-110.

35. Pramanik T, Sherpa MT, Shrestha R. Internet addiction in a group of medical students: a cross sectional study. Nepal Med Coll J 2012;14:4648.

36. Zhang MWB, Lim RBC, Lee C, Ho RCM. Prevalence of internet addiction in medical students: a meta-analysis. Acad Psychiatry 2018;42: 88-93.

37. Cheng C, Li AY. Internet addiction prevalence and quality of (real) life: a meta-analysis of 31 nations across seven world regions. Cyberpsychol Behav Soc Netw 2014;17:755-760.

38. Mak KK, Lai CM, Watanabe H, Kim DI, Bahar N, Ramos M, et al. Epidemiology of internet behaviors and addiction among adolescents in six Asian countries. Cyberpsychol Behav Soc Netw 2014;17:720-728.

39. Ni X, Yan H, Chen S, Liu Z. Factors influencing internet addiction in a sample of freshmen university students in China. Cyberpsychol Behav 2009;12:327-330.

40. Hayat AA, Kojuri J, Amini M. Academic procrastination of medical students: the role of Internet addiction. J Adv Med Educ Prof 2020;8: 83-89.

41. Tyssen R, Vaglum P, Grønvold NT, Ekeberg O. Suicidal ideation among medical students and young physicians: a nationwide and prospective study of prevalence and predictors. J Affect Disord 2001;64:
69-79.

42. Kraut R, Patterson M, Lundmark V, Kiesler S, Mukophadhyay T, Scherlis W. Internet paradox: a social technology that reduces social involvement and psychological well-being? Am Psychol 1998;53:10171031.

43. Ha JH, Yoo HJ, Cho IH, Chin B, Shin D, Kim JH. Psychiatric comorbidity assessed in Korean children and adolescents who screen positive for Internet addiction. J Clin Psychiatry 2006;67:821-826.

44. Dong G, Lu Q, Zhou H, Zhao X. Precursor or sequela: pathological disorders in people with Internet addiction disorder. PLoS One 2011;6: e14703.

45. Shepherd RM, Edelmann RJ. Reasons for internet use and social anxiety. Pers Individ Dif 2005;39:949-958.

46. Yücens B, Üzer A. The relationship between internet addiction, social anxiety, impulsivity, self-esteem, and depression in a sample of Turkish undergraduate medical students. Psychiatry Res 2018;267:313-318.

47. Schlenker BR, Leary MR. Social anxiety and self-presentation: a conceptualization model. Psychol Bull 1982;92:641-669.

48. Caplan SE. Relations among loneliness, social anxiety, and problematic Internet use. Cyberpsychol Behav 2007;10:234-242.

49. Campbell AJ, Cumming SR, Hughes I. Internet use by the socially fearful: addiction or therapy? Cyberpsychol Behav 2006;9:69-81.

50. Aydm B, San SV. Internet addiction among adolescents: the role of self-esteem. Procedia Soc Behav Sci 2011;15:3500-3505.

51. Andreassen CS, Pallesen S, Griffiths MD. The relationship between addictive use of social media, narcissism, and self-esteem: findings from a large national survey. Addict Behav 2017;64:287-293.

52. Anand N, Thomas C, Jain PA, Bhat A, Thomas C, Prathyusha PV, et al. Internet use behaviors, internet addiction and psychological distress among medical college students: a multi centre study from South India. Asian J Psychiatr 2018;37:71-77.

53. Nakayama H, Mihara S, Higuchi S. Treatment and risk factors of I nternet use disorders. Psychiatry Clin Neurosci 2017;71:492-505.

54. Haque M, Rahman NA, Majumder MA, Haque SZ, Kamal ZM, Islam $Z$, et al. Internet use and addiction among medical students of Universiti Sultan Zainal Abidin, Malaysia. Psychol Res Behav Manag 2016;9: 297-307. 